\title{
Research Article \\ The Synchrotron Radiation for Steel Research
}

\author{
Piyada Suwanpinij \\ The Sirindhorn International Thai-German Graduate School of Engineering (TGGS), \\ King Mongkut's University of Technology North Bangkok (KMUTNB), Bangkok 10800, Thailand \\ Correspondence should be addressed to Piyada Suwanpinij; piyada.s.mme@tggs-bangkok.org
}

Received 13 December 2015; Accepted 28 January 2016

Academic Editor: Hongchao Kou

Copyright (C) 2016 Piyada Suwanpinij. This is an open access article distributed under the Creative Commons Attribution License, which permits unrestricted use, distribution, and reproduction in any medium, provided the original work is properly cited.

The synchrotron X-ray radiation is a great tool in materials characterization with several advantageous features. The high intensity allows clear interaction signals and high energy of X-ray yields higher sampling volume. The samples do not need extra preparation and the microstructure is therefore not affected. With the tunability of the X-ray energy, a large range of elements and features in the samples can be investigated by different techniques, which is a significant difference between a stand-alone X-ray tube and synchrotron X-ray. Moreover, any experimental equipment can be installed through which the synchrotron beam travels. This facilitates the so-called in situ characterization such as during heat treatment, hot deformation, chemical reaction or welding. Although steel which possesses rather high density requires very high energy X-ray for large interaction volume, lower energy is still effective for the investigation of local structure of nanoconstituents. This work picks up a couple examples employing synchrotron X-ray for the characterization of high strength steels. The first case is the quantification of precipitates in high strength low alloyed (HSLA) steel by X-ray absorption spectroscopy. The other case is the in situ X-ray diffraction for phase fraction and carbon partitioning in multiphase steels such as transformation induced plasticity (TRIP) steel.

\section{Introduction}

1.1. The Synchrotron X-Ray Radiation. The development of the characterization of materials with X-ray has started over 100 years since W.C. Roentgen discovered X-ray. Since the 1940s, the synchrotron radiation has been progressively developed and become a powerful characterization tool in the last decade due to its several beneficial properties. It is an electromagnetic wave, emitted from charged particles, that is, charged particles like protons or electrons (or also positrons), forced to travel in curve during moving near the speed of light. As the particles are accelerated, a synchrotron is also known as particle acceleration equipment. The produced ray covers a broad spectrum from the range of microwave to hard X-ray, from which it can be selected to suit different required techniques. With a brightness of a million times greater than the sun and that of conventional X-ray tubes, the acquired signal from the emitted photons is high enough that samples with very dilute concentration of the investigated species can be measured. Unlike standalone X-ray tubes, synchrotron beamlines are long straight beams, through which any tailor-made experimental stations can be installed and in situ experiments can be carried out. The pulsed time structure due to bunches of produced electrons allows up to picoseconds of time-resolved investigation. Its defined polarization realizes the possibility to investigate magnetic materials. It possesses also high degree of collimation and hence increases the energy resolution. Moreover, most of the synchrotron facilities around the world open their door to international scientists through proposals. Nowadays, there are over 70 synchrotron facilities around the world: 14 in Japan, 16 in USA, 8 in Germany, and 1 in Thailand [1].

The synchrotron allows several techniques for materials characterization, that is, X-ray absorption spectroscopy (XAS), including the Extended X-Ray Absorption Fine Structure (EXAFS), X-ray diffraction (XRD), microscale X-ray fluorescence $(\mu \mathrm{XRF})$, and small angle $\mathrm{X}$-ray scattering (SAXS) as well as X-ray topography. XAS provides quantitative information of chemical species and the detailed local structure of selected atoms. The tunability of synchrotron energy enables XAS for a wide range of elements. XRD helps analyze phase fraction and residual stress as well as texture. With the advantage of high energy of synchrotron, 2-dimensional diffraction pattern from large sampling volume as well as 
in situ experiments during thermomechanical processes or tensile testing can be carried out. These two mentioned techniques are selected as examples of how synchrotron can facilitate materials characterization for high strength steels.

1.2. High Strength and Multiphase Steels and Needs of Characterization. Properties of metals can be improved by designing their microstructure. The most important trend of improving steel, as a structural material, is to improve its strength while retaining or increasing its formability. The main approaches in practice to tailor the mechanical properties in novel steels are by balancing the amount of different soft and hard phases/precipitates and controlling deformation mechanisms. The first is based on the assumption that each constituent contributes to the total strength and ductility according to the rule of mixing as if they form a composite [2]. The second involves the impeding of dislocation by small particles [3]. The last approach focuses on the competing slip and twinning mechanisms during deformation-induced martensite transformation [2].

The group of Advanced High Strength Steels (AHSSs) is the best example for designing the microstructure for the required mechanical properties. The well-known banana diagram (Figure 1) lists different AHSSs and shows the strength and ductility of each kind, compared with the classical low carbon steel. The first generation of AHSS focuses on high strength low alloyed (HSLA) steel, dual phase (DP) steel, and transformation induced plasticity (TRIP) steel. The secondgeneration concerns changing the deformation mechanism into twinning in Twinning-Induced Plasticity (TWIP) steel. Moreover, research work is active in refining the grain size into a few micrometers' size or even submicrons. Recently, a few companies launched a new commercial name of product "nanosteel," focusing on large portion of precipitates in a range of a few nanometers as well as refining the grain size, without revealing detailed information. Also, a novel process to partition the austenite stabilizer to the austenite phase from martensite such as the Quenching and Partitioning (Q\&P) process in TRIP steel is of large interest nowadays. This is because the nominal composition with low carbon can be utilized and the good weldability of TRIP steel is retained.

The HSLA steels are strengthened by fine precipitates of microalloying elements: Titanium, Vanadium, and Niobium. Different mechanisms realize the aimed high strength of this steel group: precipitation hardening by hindering the dislocation movement, grain refinement due to nucleation at precipitates, and grain growth hindrance at high temperature by TiN. In total, the type, volume fraction, and the size distribution of these precipitates determine the strength. Copper precipitate is, on the other hand, a novel concept. It is crucial to closely control the thermomechanical process during the production to optimize all the strengthening mechanisms. The resulting nanosized precipitates have to be observed conventionally by Transmission Electron Microscopy (TEM), which is quite laborious and costly and focuses only on infinitesimal sampling volume. Synchrotron XAS is a very attractive alternative in determining the type and quantifying

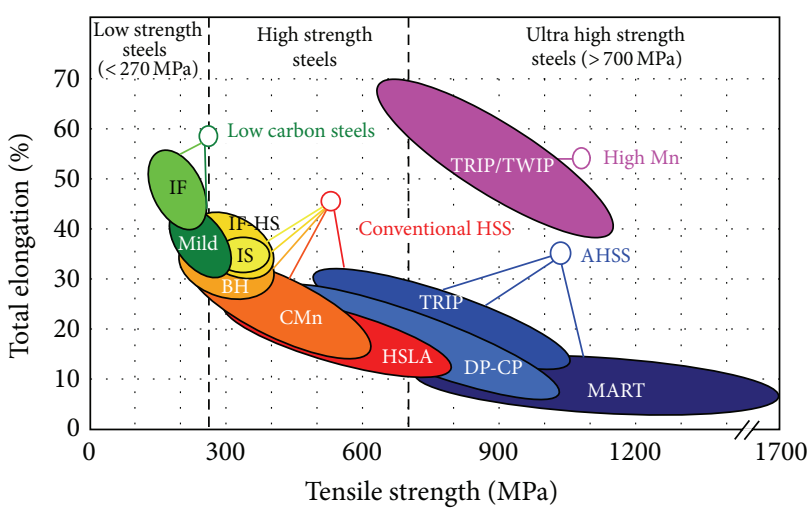

FIGURE 1: The so-called banana diagram representing the strength and ductility of different steel types. The areas of research for the third generation of AHSS are highlighted [4].

the amount of precipitates and will be the first picked-up example in this paper.

The TRIP steel exhibits exceptional higher strength with large elongation due to deformation-induced phase transformation of the retained austenite into martensite. This is strongly influenced by the austenite fraction and its stability. It is therefore quite crucial to control and characterize the fraction of retained austenite as well as the carbon content, the most important austenite stabilizer. Carbon is partitioned into the remaining austenite during preceding phase transformations, that is, austenite to ferrite followed by carbidefree bainite, and therefore is a function of production process parameters. Most characterization techniques face the challenges by the fact that only shallow volume near the surface can be investigated. This region is nevertheless very much sensitive to the sample preparation. The $\mathrm{Q} \& \mathrm{P}$ process stabilizes the retained austenite from low carbon nominal composition by back diffusion of carbon from martensite. The conventional procedures such as dilatometry, metallography, and Scanning Electron Microscopy (SEM) could hardly reveal this nanomorphology. Working with carbon partitioning between these nanoconstituents by the synchrotron yields several advantages that much larger volume can be illuminated with high energy X-ray. Also, as different equipment can be installed at the beamlines, in situ investigation of the alteration in austenite phase both during the production process and under loading can be successfully performed. This is the second case to discuss in this paper.

\section{XAS for the Investigation of Precipitates in Steels}

XAS spectra record photoelectric absorption from the interaction between matter and energy-tunable X-ray. When photon energy of the incoming $\mathrm{X}$-ray is about to be higher than binding energy between core-level electron and nucleus, the X-ray photon energy will be absorbed and then will knock the core electron out as a photoelectron. This absorption will be seen as a sharp rise at a specific energy, a socalled absorption edge, in the spectrum. Each element shows 


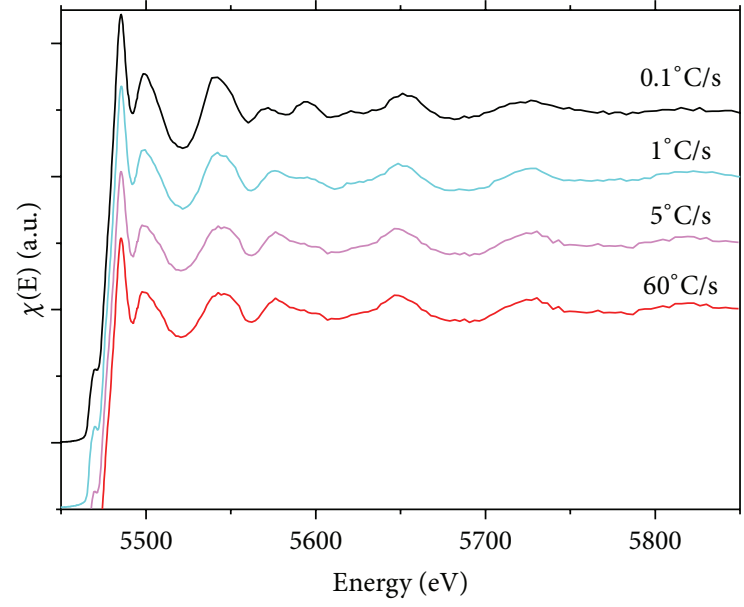

(a)

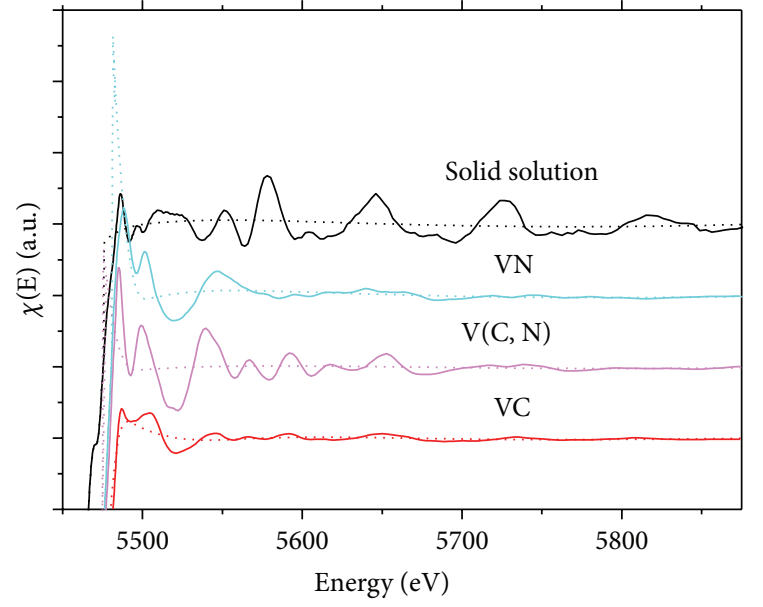

(b)

FIGURE 2: XAS spectra of (a) simulated hot rolled samples with different cooling rates, compared with (b) standard compounds of Vanadium and a sample in which Vanadium is completely dissolved.

different characteristic absorption edge for their different electron-shell energies. The emitted photoelectron causes a core-hole in the electron shell that results in another electron from the outer shells replacing the lost electron. $\mathrm{X}$-Ray Absorption Near Edge Spectroscopy (XANES) is the region near the absorption edge. The shift in energy of the absorption edge indicates the type and oxidation state of the absorbing atom $[5,6]$. More structural information can be obtained from the oscillation in the Extended X-Ray Absorption Fine Structure (EXAFS) which is extended far behind the absorption edge. As the photoelectron emitted from the central atom during the X-ray absorption can be scattered by the surrounding atoms, it results in constructive and destructive interferences in the spectrum. Hence, each metal or compound has its own fingerprint spectral shape and features, due to the character of surrounding elements and how they are arranged in the structure. In a mixed system with more than one phase containing the absorbing atom, the EXAFS shows the summation of fingerprint spectra of those compounds in the mixture.

XAS technique has been applied for different steels at beamline BL8 of the Siam Photon Laboratory (SPL) at Synchrotron Light Research Institute (SLRI), Nakhon Rachasima, Thailand. The first investigation, as published elsewhere [7], reveals the type and amount of Vanadium precipitates as a result of the cooling rate after simulated hot rolling process in HSLA steel. The size of Vanadium precipitates varies from several nanometers to $70 \mathrm{~nm}$ by Scanning Transmission Electron Microscopy (STEM). As the final cooling rate during ferrite formation was the only variable, the precipitation in ferrite should contribute mainly to dislocation looping proposed by Orowan. The measured spectra of the samples plotted in Figure 2(a) are compared with the standard spectra of the possible type of Vanadium compounds as well as dissolved atoms of Vanadium in iron solid solution, in Figure 2(b). The calculated fraction of each species was performed by Linear Combination Fit (LCF) and is

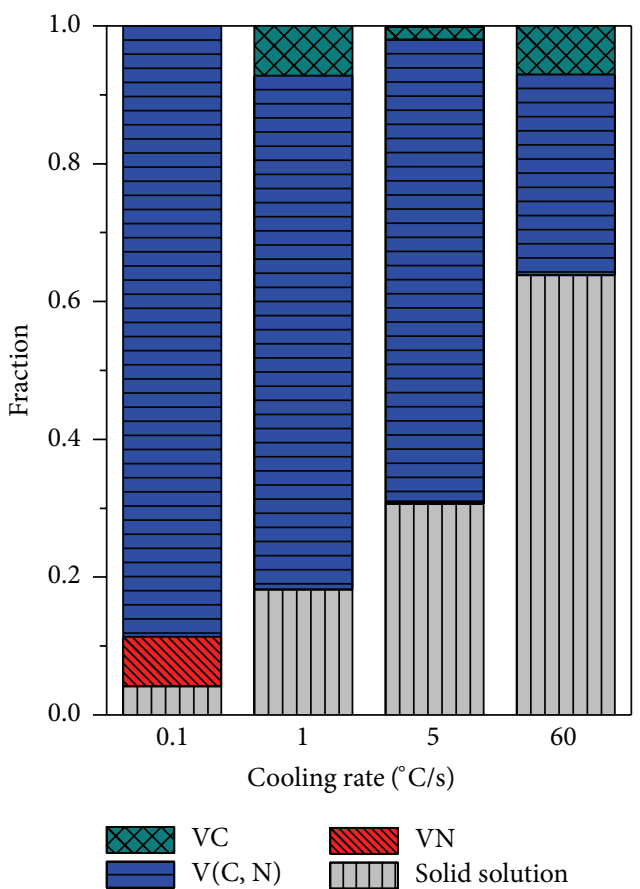

FIGURE 3: Calculated fraction of different precipitates of Vanadium compared with the fraction of Vanadium left in the solid solution by different cooling rates.

presented in Figure 3. It can be concluded that slower cooling rates facilitate the precipitation of $\mathrm{V}(\mathrm{C}, \mathrm{N})$ which should allow the most effective precipitation hardening.

The second work measures the precipitation of Copper in 18CrNiMo7-6 martensitic carburizing steel. Similar to the $\mathrm{Cu}$-alloying concept in HSLA steels, Copper of $1.0 \%$ and $1.5 \%$ mass was added to investigate the improvement of rolling contact fatigue in gear steel by nanosized precipitate which enhances the strain hardening behavior [8]. While the yield 


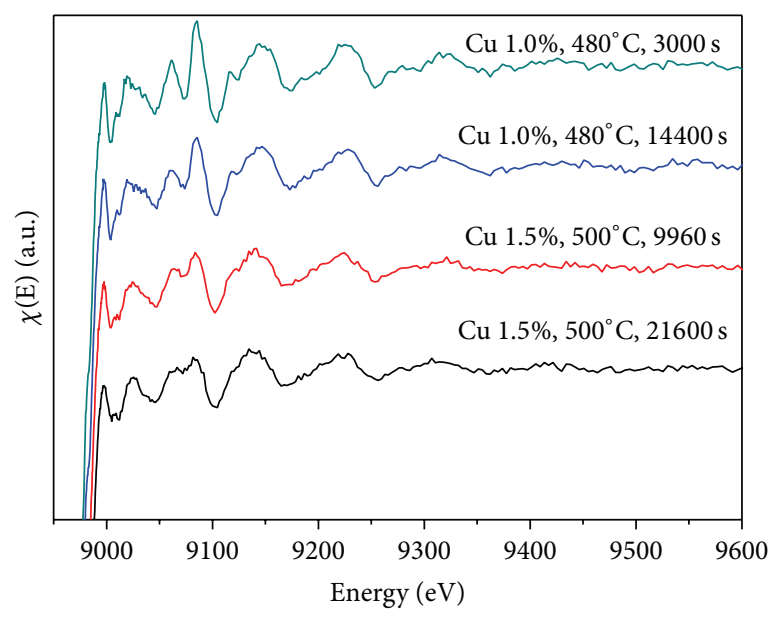

(a)

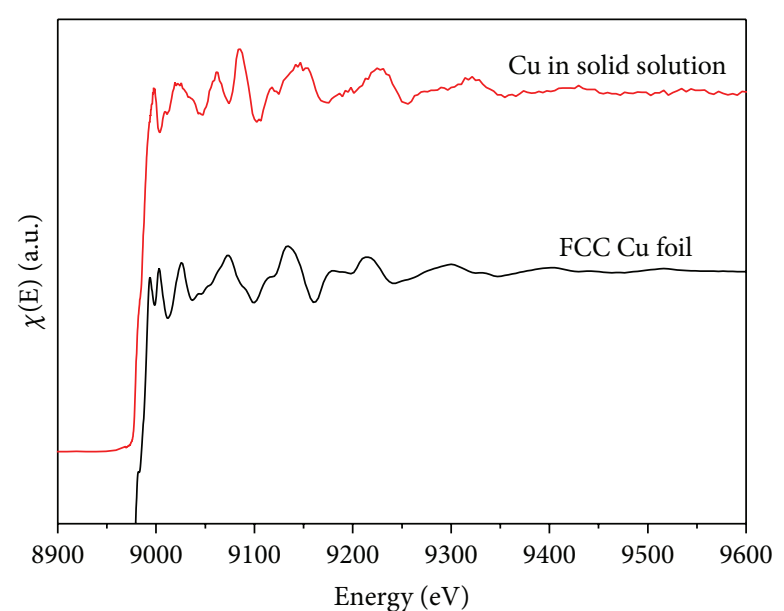

(b)

FIGURE 4: The XAS spectra of (a) Cu-added samples after different ageing treatments, compared with (b) standard Copper foil and solution annealed sample.

TABLE 1: Calculated fraction of FCC Copper precipitates and Copper atoms in the solid solution in $18 \mathrm{CrNiMo} 7-6$ carburizing steel with different heat treatment conditions.

\begin{tabular}{lcc}
\hline & FCC Cu & $\mathrm{Cu}$ in solid solution \\
\hline $1.5 \% \mathrm{Cu}$, aged at $500^{\circ} \mathrm{C}$ for $21600 \mathrm{~s}$ & 0.564 & 0.436 \\
$1.5 \% \mathrm{Cu}$, aged at $500^{\circ} \mathrm{C}$ for $10000 \mathrm{~s}$ & 0.459 & 0.541 \\
$1.0 \% \mathrm{Cu}$, aged at $480^{\circ} \mathrm{C}$ for $14400 \mathrm{~s}$ & 0.282 & 0.718 \\
$1.0 \% \mathrm{Cu}$, aged at $480^{\circ} \mathrm{C}$ for $3000 \mathrm{~s}$ & $0.173^{*}$ & $0.827^{*}$ \\
\hline
\end{tabular}

${ }^{*}$ Can be inaccurate as coherent BCC Cu precipitates are expected.

strength is the most effectively increased in case of coherent BCC Copper [9], larger incoherent Copper precipitates lead to the increase in strain hardening rate $[10,11]$. Both types of steels were therefore aged at different temperature and time to test for the improved strain hardening.

While getting only very weak signal by Small Angle Neutron Scattering (SANS) in the sample with lower amount of Copper with shortest aging time, the synchrotron XAS shows clear spectra of the Copper precipitate as plotted in Figure 4(a). By means of the LCF, the amount of the Copper precipitate and Copper atoms in the solid solution can be quantified in mass percentage. By ageing the $1.5 \%$ Copperadded steel at $500^{\circ} \mathrm{C}$ for $10000 \mathrm{~s}$, more than half of the Copper atoms are precipitated while the rest are in the solid solution. The Copper precipitates consume more than half of the available Copper atoms when the annealing time exceeds 6 hours. More Copper atoms are found as solute atoms when ageing at $480^{\circ} \mathrm{C}$ in the $1 \%$ Copper-added steel. The XAS spectra of samples are compared with the standard spectra of FCC Copper and solution-annealed sample (Figure 4(b)), representing Copper in iron solid solution. The fraction of each state of Copper atom was calculated and shown in Table 1.

The precipitation sequence begins with the formation of metastable BCC-Cu-clusters coherent with the steel matrix as reported in [12]. Therefore, in case of short ageing duration in which only small fraction of Copper precipitate is observed, a standard spectrum of BCC Copper shall be prepared. This is in an ongoing work by means of ab initio multiple scattering calculations such as FEFF $[13,14]$. Therefore, the reported fractions of 0.173 and 0.827 for $1.0 \% \mathrm{Cu}$-added sample, aged at $480^{\circ} \mathrm{C}$ for $3000 \mathrm{~s}$, can be still inaccurate.

\section{High Energy XRD for Polymorphism in Steels}

Phases with different crystal structures can be determined by conventional XRD. Employing the high energy X-ray generated by synchrotron facilities enables several advantages. Firstly, a significantly larger sampling volume can be illuminated. Secondly, different experimental equipment can be installed through which the X-ray beam penetrates. With fast detector the XRD patterns can be recorded every few seconds for in situ investigation. Thirdly, extra sample preparation does not require that sensitive phases do not transform.

The first example of in situ investigation of AHSS is during simulated thermomechanical process for the phase transformation kinetics of hot-rolled Si-TRIP steel as well as the carbon partitioning phenomenon and has been published earlier [15] in detail. A very hard X-ray beam of $100 \mathrm{keV}$ penetrated through the diameter of the samples in a deformation dilatometer (Figure 5). The 2-dimensional solid state detector behind the experimental unit recorded the diffraction pattern every 3 s. Figure 6 is a converted 1-dimensional diffraction pattern during the holding time of bainite transformation at $450^{\circ} \mathrm{C}$. It reveals the development of the BCC phase of bainitic ferrite while the FCC phase of austenite decreases. The work confirms the importance of the predeformation, corresponding to the retained strain at last finishing stands during hot rolling, in accelerating the ferrite formation and carbon partitioning to stabilize enough fraction of retained austenite in the final product. The lattice parameter of austenite can be measured successfully as illustrated in Figure 7 and proves the carbon enrichment during the formation of 


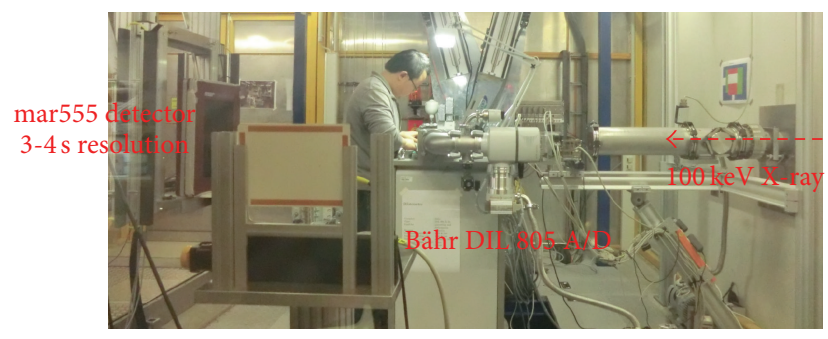

FIgURE 5: The configuration of X-ray beam, experimental equipment, and 2-dimensional detector in the experimental hutch during the in situ high energy XRD measurement at the engineering materials science streamline HARWI II radiated from DORIS storage ring (Deutsches Elektronen-Synchrotron), Hamburg, Germany.

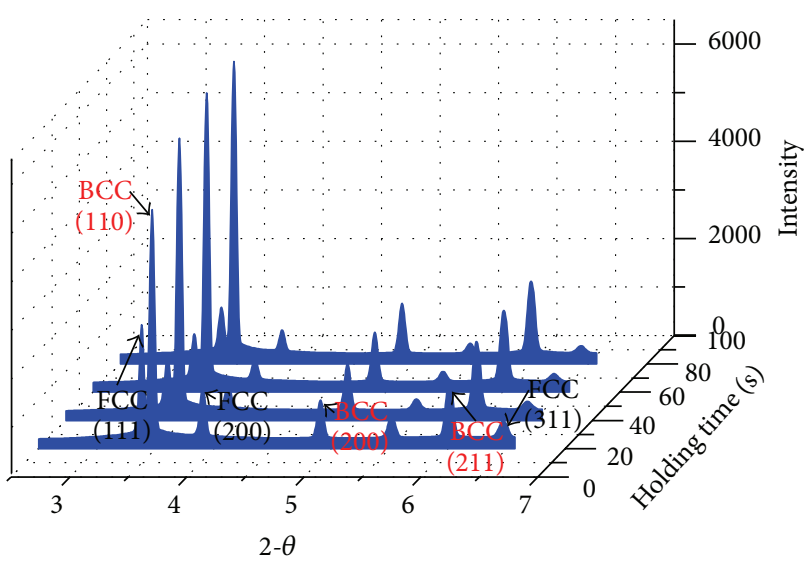

FIGURE 6: The alteration of converted 1-dimensional diffraction pattern during the bainite transformation step during the thermomechanical process of hot rolled TRIP steel observed by in situ XRD.

carbide-free bainite. Figure 8 represents the stability of the austenite during quenching after the process. Longer carbon partitioning time during the bainitic transformation stabilizes the austenite greatly. Hence, the austenite fraction barely drops during quenching in the samples after longer holding time at $450^{\circ} \mathrm{C}$.

The second research work was carried out earlier [16] at the same beamline with the same equipment to investigate the carbon partitioning during the Q\&P heat treatment of a TRIP steel. It was discovered that the quenching temperature is not important for the final austenite fraction at room temperature. It implies a simple and robust Q\&P process in the scope of study. However, too small fraction retained austenite has been found from the investigated cycles and has to be increased for significant TRIP effect. The results cannot be observed by dilatometry as the signals are too weak.

Similarly, the deformation-induced martensite formation can be observed by installing a testing device such as tensile rig across the beam. Therefore, the TRIP and TWIP steels can be studied in situ for the effect of strain, strain rate, and temperature on the stability of martensite to relate to its strength. Although the martensitic transformation in TRIP steel is usually considered to be only strain-induced, the microstrain analysis in the recent work by Jung et al. [17] reveals

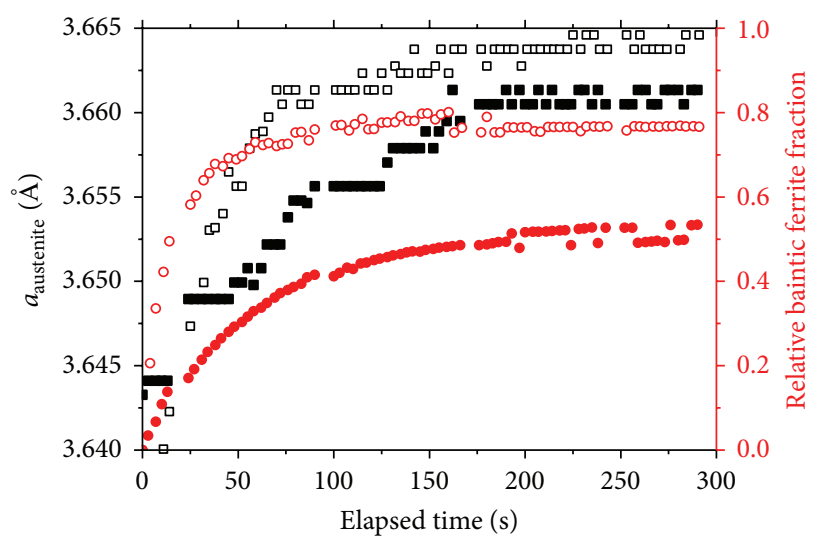

Hollow: $\varepsilon=0.0$ (ferrite fraction $\sim 0.5$ )

Solid: $\varepsilon=0.6$ (ferrite fraction $\sim 0.7$ )

FIGURE 7: The measured lattice parameter of austenite during the formation of the carbide-free bainite, implying the carbon enrichment in austenite.

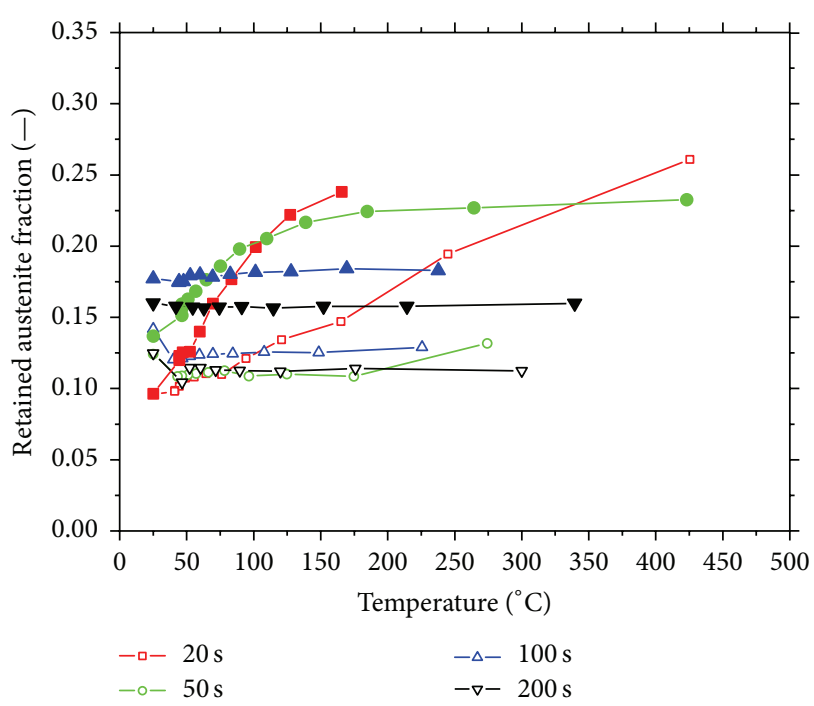

FIgURE 8: The change in the austenite fraction during quenching, implying the stability in austenite after different time during bainitic transformation at $450^{\circ} \mathrm{C}$.

that it can be also stress-induced. A comprehensive work performed by [18] gave a deeper understanding on the alternating interaction between slipping and twinning in different strain regions, resulting in the high ductility and high work hardening rate in TWIP steel. Also, the final texture is governed by slipping. The low range of strain rates between $10^{-4}$ and $10^{-1} \mathrm{~s}^{-1}$ has limited influence on twinning. The transformation into hexagonal $\varepsilon$ martensite is not limited only to the case of low stacking fault energy but is also activated in this case under large shear strain [19].

The XRD technique is quite well-established and is in operation of world leading beamlines. Other beamlines with lower energy might result in much lower penetrated volume, according to the calculation via Beer-Lambert's law. Another remark shall be that the lattice parameter for the calculation 
of carbon content is an average value, nevertheless from relatively large sampling volume under very high energy $\mathrm{X}$-ray.

\section{Conclusions and Outlook}

Although modern steel industry has been settled since the 1850s, its progress of development never stops. New groups of steels or with different alloying concepts are more and more developed for improved properties in various purposes. With that, new phases and constituents must be more investigated as the influence of the manufacturing process as a part of research for materials development.

High strength steels and multiphase steels contain some constituents that need special caution during the characterization such as unstable phase or minute particles. Employing synchrotron with higher energy X-ray enables deeper penetration and larger sampling volume. Hence, the surface preparation is of much less importance. This means the susceptible phases are not interfered with by the surface preparation and it results in more accurate results.

There are various available useful techniques by synchrotron radiation. The proper characterization techniques must be able to detect or at best quantify the features of interest in the microstructure. The features which cannot be obtained by conventional methods should be firstly considered as they determines why the synchrotron is needed. Then, the limitations must be also considered. For example, the elements expected to be investigated might not be possible to be scanned such as lighter elements by XAS.

Having its door opened to everyone, researchers can seek for suitable beamlines in even another continent. As the development of synchrotron technology keeps going forward, the 4th generation of synchrotron radiation, which is laser source, has arrived. Other parts such as optical devices and detectors are also progressively improved. As higher data acquisition rate can be obtained, in situ measurements become even more accurate. Altogether, all factors shall bring momentous evolution in materials characterization.

\section{Conflict of Interests}

The author declares that there is no conflict of interests regarding the publication of this paper.

\section{Acknowledgment}

The author would like to thank a few sources of funding that allow them to gather all valuable findings and great experience in this field: SPP1204 and BL402/32-1 projects granted by the German Research Foundation (DFG), Thai-German Seed Fund Project issued by the Exploratory Research Space at RWTH Aachen University, Germany (ERS), and Project no. TRG5780214 granted by The Thailand Research Fund (TRF).

\section{References}

[1] http://www.lightsources.org/light-source-facility-information.

[2] M. Y. Demeri, Advanced High-Strength Steels: Science, Technology, and Applications, 2013.
[3] J. Lu, O. Omotoso, J. B. Wiskel, D. G. Ivey, and H. Henein, "Strengthening mechanisms and their relative contributions to the yield strength of microalloyed steels," Metallurgical and Materials Transactions A, vol. 43, no. 9, pp. 3043-3061, 2012.

[4] Advanced High Strength Steel (AHSS) Application Guidelines, IISI Committee on Automotive Applications, March 2005.

[5] J. E. Penner-Hahn, "X-ray absorption spectroscopy", in Comprehensive Coordination Chemistry II, J. A. McCleverty and T. J. Meyer, Eds., chapter 2.13, pp. 159-186, Pergamon Press, Oxford, UK, 2003.

[6] J. J. Rehr and R. C. Albers, "Theoretical approaches to X-ray absorption fine structure," Reviews of Modern Physics, vol. 72, no. 3, pp. 621-654, 2000.

[7] P. Suwanpinij, H. H. Dickert, N. Thammajak, and P. Srichareonchai, "Quantification of vanadium precipitates in HSLA steel by synchrotron X-ray absorption spectroscopy (XAS)," Materials Testing, vol. 58, no. 1, pp. 5-11, 2016.

[8] M. D. Bambach, W. Bleck, H. S. Kramer et al., "Tailoring the hardening behavior of 18CrNiMo7-6 via Cu alloying," Steel Research International, 2015.

[9] J. Takahashi, K. Kawakami, and Y. Kobayashi, "Consideration of particle-strengthening mechanism of copper-precipitationstrengthened steels by atom probe tomography analysis," Materials Science and Engineering A, vol. 535, pp. 144-152, 2012.

[10] M. F. Ashby, "The deformation of plastically non-homogeneous materials," Philosophical Magazine, vol. 21, no. 170, pp. 399-424, 1970.

[11] R. E. Smallman and R. J. Bishop, Modern Physical Metallurgy and Materials Engineering, Butterworth-Heinemann, Oxford, UK, 1999.

[12] K. Osamura, H. Okuda, M. Takashima, K. Asano, and M. Furusaka, "Small-angle neutron scattering study of phase decomposition in Fe-Cu binary alloy," Materials Transaction JIM, vol. 34, no. 4, pp. 305-311, 1993.

[13] J. J. Rehr and R. C. Albers, "Scattering-matrix formulation of curved-wave multiple-scattering theory: application to x-rayabsorption fine structure," Physical Review B, vol. 41, no. 12, pp. 8139-8149, 1990.

[14] http://www.feffproject.org/.

[15] P. Suwanpinij, A. Stark, X. Li et al., "In situ high energy Xray diffraction for investigating the phase transformation in hot rolled TRIP-aided steels," Advanced Engineering Materials, vol. 16, no. 8, pp. 1044-1051, 2014.

[16] T. Rieger, K. Herrmann, D. Carmele et al., "'Quenching and partitioning' - an in-situ approach to characterize the process kinetics and the final microstructure of TRIP-assisted steel," Advanced Materials Research, vol. 409, pp. 713-718, 2012.

[17] J. Jung, H. Kim, and B. C. De Cooman, "Yielding behavior of $\mathrm{Nb}$ micro-alloyed C-Mn-Si TRIP steel studied by in-situ synchrotron X-ray diffraction," ISIJ International, vol. 50, no. 4, pp. 620-629, 2010.

[18] K. Yan, D. G. Carr, M. D. Callaghan, K.-D. Liss, and H. Li, "Deformation mechanisms of twinning-induced plasticity steels: in situ synchrotron characterization and modeling," Scripta Materialia, vol. 62, no. 5, pp. 246-249, 2010.

[19] K. Yan, In-situ characterization by high-energy X-ray and neutron diffraction of micro-structural evolution of selected materials during thermo-mechanical processing [Doctor of Philosophy Thesis], School of Mechanical, Materials and Mechatronics Engineering, University of Wollongong, Wollongong, Australia, 2012, http://ro.uow.edu.au/theses/3700/. 

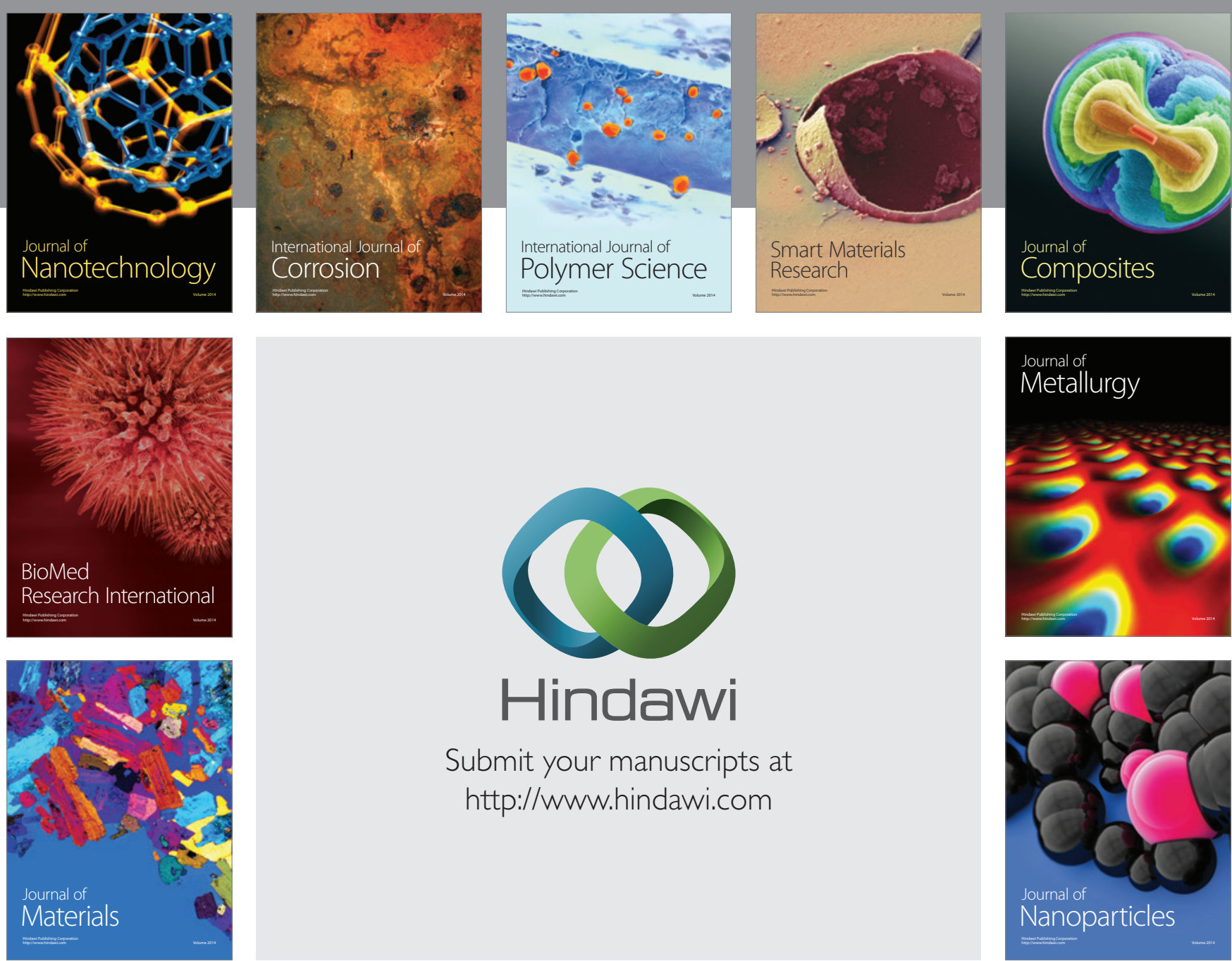

\section{Hindawi}

Submit your manuscripts at

http://www.hindawi.com

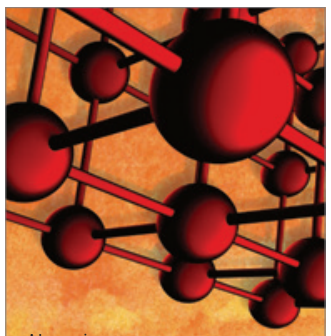

Materials Science and Engineering
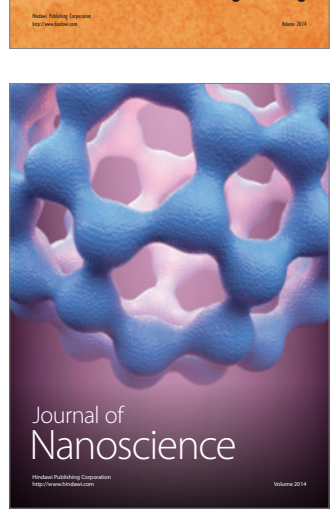
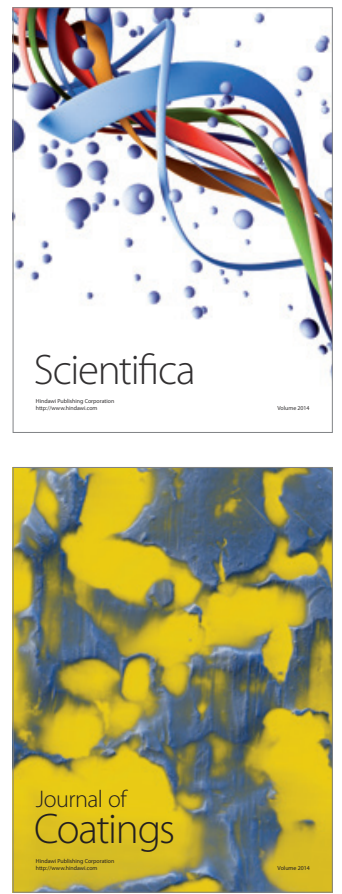
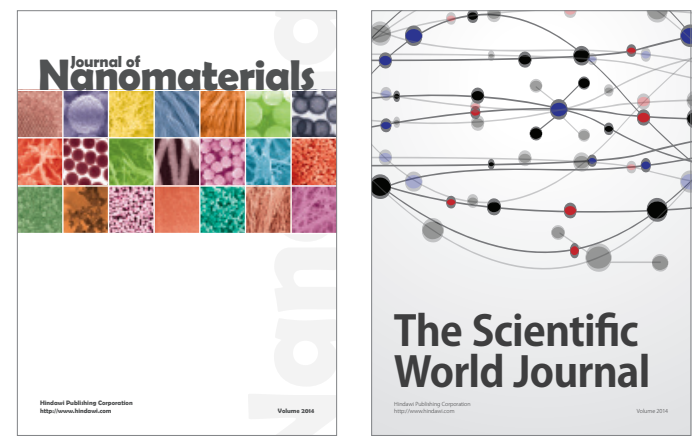

The Scientific World Journal
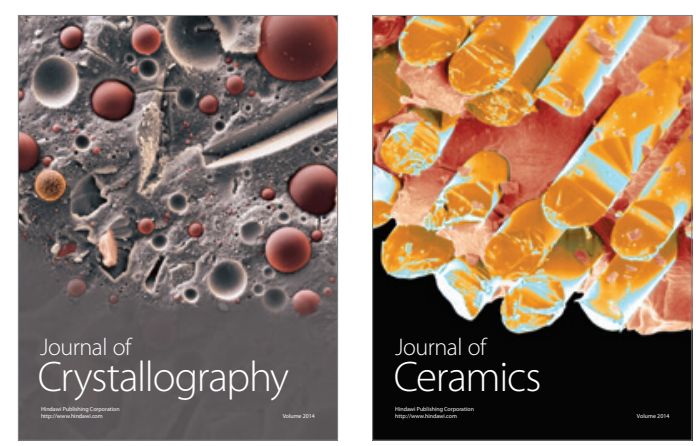
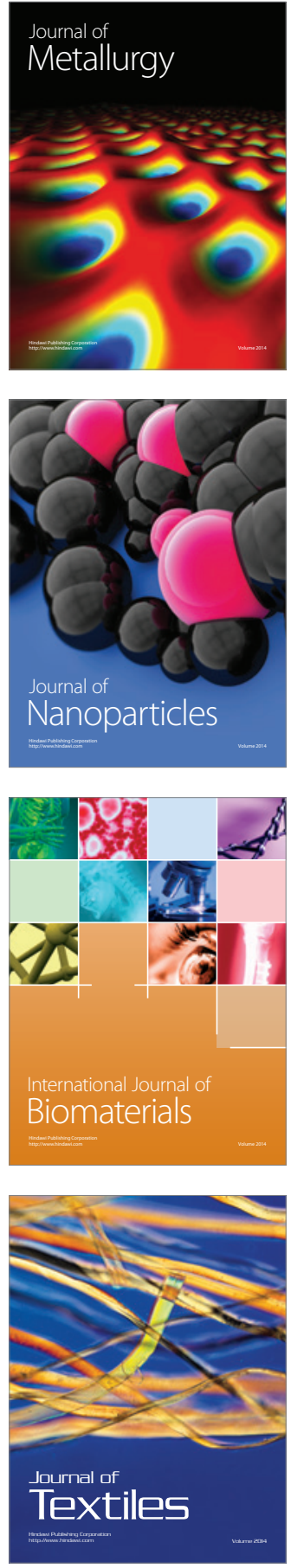